\title{
ANALISIS STRATEGI MANAJEMEN PT HANJAYA MANDALA SAMPOERNA TBK. UNTUK MENJADI MARKET LEADER DALAM INDUSTRI ROKOK
}

\author{
Sri Septia \\ Program Studi Magister Manajemen Universitas Tarumanagara \\ tia.ruya@yahoo.com \\ Riris Loisa \\ Program Studi Magister Manajemen Universitas Tarumanagara
}

Masuk : 30-11-2019, revisi : 20-12-2019 diterima untuk diterbitkan : 21-12-2019

\begin{abstract}
The purpose of research at PT HM Sampoerna, Tbk is to assess the company's business in the period 2013-2017. The results of the business assessment of each company can be information for investors and creditors to make a decision whether it is good for them to rotate the assets they have in the company. Business performance assessment conducted by the author at PT HM Sampoerna, Tbk is analyzing the SWOT, PORTER, PEST (Political, Economic, Social, and Technology) strategies, analyzing financial statements, and analyzing bankruptcy. The author uses a mixture of qualitative and quantitative methods in the research approach by using the income statement and balance sheet obtained from secondary data where all data is publicly available and can be accessed by anyone. Data analysis uses library research and analysis procedures. The results showed the level of leverage ratios and the level of liquidity ratios at PT HM Sampoerna, Tbk experienced fluctuations in each year but remained above the average industry company. While the level of profitability ratios has increased and is also well above the average industry company. The results of the analysis of the $\mathrm{z}$ score of PT HM Sampoerna, Tbk are far from the level of bankruptcy. Researchers can give advice to PT HM Sampoerna, Tbk to improve their income by changing credit sales to cash sales and also by looking at the strengths, weaknesses, opportunities and obstacles owned by PT HM Sampoerna, Tbk.
\end{abstract}

Abstrak : Tujuan penelitian pada PT HM Sampoerna, Tbk adalah untuk menilai bisnis perusahaan pada periode 2013 - 2017. Hasil dari penilaian bisnis pada setiap perusahaan dapat menjadi informasi bagi para investor dan kreditor untuk mengambil keputusan apakah bagus bagi mereka untuk memutar asset yang dimilikinya pada perusahaan tersebut. Penilaian kinerja bisnis yang dilakukan oleh penulis pada PT HM Sampoerna, Tbk adalah menganalisis strategi SWOT, PORTER, PEST (Politic, Economi, Social, and Technology), menganalisis laporan keuangan, dan menganalisis kebangkrutan. Penulis menggunakan metode campuran antara kualitatif dan kuantitatif dalam pendekatan penelitian dengan menggunakan laporan laba rugi dan neraca yang didapat dari data sekunder dimana semua data telah tersedia secara umum dan dapat diakses oleh siapapun. Analisis data menggunakan studi kepustakaan dan prosedur analisis. Hasil penelitian menunjukkan tingkat rasio leverage dan tingkat rasio likuiditas pada PT HM Sampoerna, Tbk mengalami fluktuatif atau naik turun pada setiap tahunnya namun tetap berada diatas rata-rata industri perusahaan. Sedangkan tingkat rasio profitabilitas mengalami peningkatan dan juga berada jauh diatas rata - rata industri perusahaan. Hasil analisis $z$ score PT HM Sampoerna, Tbk berada jauh dari tingkat kebangrutan. Peneliti dapat memberikan saran pada PT HM Sampoerna, Tbk untuk meningkatkan pendapatanya dengan cara merubah penjualan kredit menjadi penjualan cash dan juga dengan melihat kekuatan, kelemahan, peluang dan hambatan yang dimiliki oleh PT HM Sampoerna, Tbk. 
Keywords : Analisis Strategi SWOT, PORTER, PEST, Laporan Keuangan, Analisis Kebangkrutan.

\section{PENDAHULUAN}

Perkembangan industri rokok memicu perkembangan sektor industri jasa dan perdagangan. Data dari Badan Pusat Statistik (BPS) menjelaskan bahwa cukai hasil rokok merupakan salah satu sumber pendapatan terbesar negara dari dalam negeri, terbukti pada tahun 2018, penerimaan cukai menjadi 155,4 triliun dari sebelumnya 153,1 triliun pada tahun 2017, hal ini menunjukan perkembangan perusahaan rokok di Indonesia mengalami peningkatan yang cukup bagus. Perkembangan industri rokok yang pesat membawa implikasi pada persaingan antar perusahaan dalam industri. Perusahaan juga dituntut untuk mempertahankan atau bahkan meningkatkan kinerjanya agar tetap bertahan dalam masa krisis maupun persaingan yang ketat. Ibarat dua sisi mata uang, industri rokok dibutuhkan tetapi di sisi lain ruang geraknya dibatasi.

Analisis bisnis dapat dilakukan oleh investor atau kreditor dengan pendekatan analisis strategi, anlisis modal, merger, dan lainya (Porter, 1980, 1985). Hal ini dilakukan agar investor atau kreditor teliti dalam mengambil keputusan tentang dimana dan seberapa besar dana mereka ditanam. Pada PT HM Sampoerna Tbk dapat dilakukan pendekatan seperti analisis strategi, analisis SWOT, Porter, PESTEL analysis (Political, Economic, Social, and Technology), analisis laporan keuangan dan analisis kebangkrutan (Pearce\& Robinson, 2013 ; Michael E Porter, 1985 ; Afriyeni, 2008 ; Edward Altman, 1968). Investor dan kreditor juga harus membandingkan hasil penilaian bisnis suatu perusahaan dengan perusahaan sejenis, agar dapat menilai kinerja bisnis suatu perusahaan jika dibandingkan dengan kinerja bisnis perusahaan sejenis.

Oleh sebab itu, melihat pentingnya penilaian bisnis bagi para investor dan kreditor, penulis tertarik untuk membuat "Analisis Strategi Manajemen PT Hanjaya Mandala Sampoerna Tbk. Untuk Menjadi Market Leader Dalam Industri Rokok"

\section{LANDASAN TEORI}

\section{Laporan Keuangan}

SAK (2002) Menyatakan Laporan keuangan adalah catatan informasi keuangan suatu perusahaan pada suatu periode akuntansi yang dapat digunakan untuk menggambarkan kinerja perusahaan tersebut. Laporan keuangan adalah bagian dari proses pelaporan keuangan.

\section{Penilaian Bisnis}

Mengacu pada pendapat Palepu, Healy dan Peek (2004) penilaian bisnis adalah titik awal penting dalam menganilisis laporan keuangan. Penilaian bisnis mengidentifikasi keuntungan dan resiko - resiko utama perusahaan derta memungkinkan penganalisa untuk menilai keberlanjutan kinerja perusahaan saat ini dan membuat ramalan yang realistis terhadap kinerja masa depan.

\section{Analisis Kebangkrutan}

Analisis kebangkrutan adalah suatu alat yang digunakan untuk meramalkan tingkat kebangkrutan suatu perusahaan dengan menghitung nilai dari beberapa rasio lalu kemudian dimasukkan dalam suatu persamaan diskriminan.

\section{METODE PENELITIAN}

\section{Jenis dan Sumber Data}

Penulis menggunakan pendekatan kuantitatif dalam melakukan penelitiannya. Pendekatan kuantitatif digunakan dalam pengolahan data guna mencari kesimpulan dari hasil analisis yang dilakukan. Sumber data yang digunakan penulis adalah data sekunder dimana semua data yang didapatkan dalam proses penelitian telah tersedia secara umum dan dapat diakses oleh siapapun. 


\section{Penentuan Jumlah Sampel}

Sampel yang akan digunakan sebanyak dua perusahaan pembanding dengan jangkauan laporan keuangan selama lima tahun yaitu tahun 2013 - 2017. Sampel pembanding ini untuk melihat rata - rata rasio industri sejenis sebagai acuan untuk menilai rasio keuangan PT. HM Sampoerna, Tbk dibandingkan dengan industri sejenis.

\section{Metode Pengumpulan Sampel}

Penelitian ini menggunakan data sekunder berupa laporan keuangan tahunan PT. HM Sampoerna, Tbk. Pengumpulan data dilakukan dengan mendokumentasikan data - data laporan keuangan tahunan PT. HM Sampoerna, Tbk dari tahun 2013 hingga tahun 2017 yang diperoleh dari laporan keuangan yang dipublikasikan secara online melalui website PT. HM Sampoerna, Tbk dan www.idx.co.id.

\section{Metode Analisis Data}

Dengan melakukan beberapa pendekatan penilaian bisnis terkait dengan strategi dan laporan keungan yang dimilik oleh PT. HM Sampoerna, Tbk. Pendekat tersebut adalah : analisis strategi (SWOT, PEST, PORTER), analisis laporan keuangan dan analisis kebangkrutan (Pearce\& Robinson, 2005 ; Michael E Porter, 1985 ; Afriyeni , 2008 ; Edward Altman, 1968).

\section{HASIL PENELITIAN DAN PEMBAHASAN Analisis SWOT \\ Internal Perusahaan}

\section{Kekuatan}

Menguasai pangsa pasar : Produk - produk rokok sampoerna secara keseluruhan menguasai pangsa pasar rokok Indonesia dengan pangsa pasar 35\%, posisi kedua Gudang Garam 21,5\%, dan ketiga Djarum 19,3\%.

2. Kelemahan

Harga yang cukup mahal

\section{Eksternal Perusahaan}

1. Peluang

Trend pasar positif untuk rokok Low Tar Low Nicotine (LTLN) di Indonesia

2. Ancaman

Regulasi pergub mengenai anti - rokok

\section{Analisis Porter}

1. Persaingan dengan perusahaan sejenis

Ada beberapa perusahaan yang memiliki bidang perusahaan yang sama dengan PT. HM Sampoerna, Tbk dan masuk ditingkat rokok perusahaan rokok besar di Indonesia.
a. PT. Gudang Garam, Tbk
b. PT. Bentoel Internasional Investama

2. Ancaman dari pesaing baru

Pesaing baru yang datang bagi PT HM Sampoerna, Tbk hanyalah perusahaan lama yang mengeluarkan produk - produk barunya. Seperti PT Gudang Garam, Tbk yang membuat rokok mild yaitu Surya Siganature dan juga PT Bentoel yang mempunyai produk Star Mild, produk - produk tersebut bersaing dengan produk - produk Sampoerna Mild milik PT. HM Sampoerna, Tbk.

3. Ancaman dari produk subtitusi

Produk subtitusi yang kini cukup diminati konsumen antara lain rokok elektrik, rokok cair dan permen karet nikotin, dan jika kualitas dari sampoerna menurun konsumen dapat mengganti ke produk rokok perusahaan pesaing. 


\section{Analisis PEST}

1. POLITIK

Badan Penyelenggara Jaminan Sosial (BPJS) Ketenagakerjaan dan Kesehatan yang wajib diberikan kepada para pekerja, selain sebagai kewajiban perusahaan untuk menjaga keselamatan pekerja, juga untuk menaati peraturan pemerintah yang berlaku.

2. EKONOMI

Inflasi yang semakin tinggi dapat berdampak pada kegiatan operasional maupun non operasional perusahaan yang membuat biaya penyediaan manjadi tinggi yang diakibatkan oleh nilai tukar rupiah ke dollar yang turun.

3. SOSIAL

PT HM Sampoerna Tbk, mengoperasikan Sampoerna Enterpreneurship Training Center (SETC), yang telah memfasilitasi beberbagai pelatihan untuk lebih dari 22.000 peserta, telah menciptakan sekitar 3.300 usaha kecil dan menengah di Indonesia sejak pertama kali didirikan dan mendapatkan kehormatan dalam Social Enpowerment dan Responsible Business Leader dalam ajang Asia Resposible Entrepreneurship Awards (AREA) tahun 2015.

\section{TEKNOLOGI}

Sampoerna memiliki Laboratorium Scientific Technical Services (STS) yang terletak di Pasuruan, Jawa Timur.

\section{Analisis Rasio Laporan Keuangan}

\section{Analisis Rasio Likiuditas}

Hasil perhitungan dari analisis rasio likuiditas PT HM Sampoerna Tbk tahun 2013 -

2017 adalah sebagai berikut :

Tabel 1.1

Perhitungan Rasio Likuiditas

\begin{tabular}{|l|c|c|c|c|c|}
\hline \multirow{2}{*}{$\begin{array}{l}\text { Rasio } \\
\text { Rasio Likuiditas }\end{array}$} & \multicolumn{5}{|c|}{ PT. HM Sampoerna Tbk. } \\
\cline { 2 - 6 } & $\mathbf{2 0 1 3}$ & $\mathbf{2 0 1 4}$ & $\mathbf{2 0 1 5}$ & $\mathbf{2 0 1 6}$ & $\mathbf{2 0 1 7}$ \\
\hline Current Ratio & 1.75 & 1.53 & 6.57 & 5.23 & 5.27 \\
Acid Test Ratio & 0.32 & 0.25 & 2.37 & 2.21 & 2.49 \\
Receivable & & & & & \\
Turnover & 53.85 & 79.92 & 36.23 & 28.73 & 27.54 \\
Inventory Turnover & 3.05 & 3.45 & 3.53 & 3.68 & 4.15 \\
\hline
\end{tabular}

1. Current Ratio

Pada tahun 2014 menunjukkan penurunan aktiva lancar sebesar -2,2\% sedangkan hutang lancarnya meningkat hingga 12,3\%, pada tahun 2015 terjadi peningkatan asset lancar sebesar 33,9\% hal ini juga diikuti dengan penurunan hutang lancar yang mencapai $-59,7 \%$, ini baik bagi perusahaan. Pada tahun 2016 kembali peningkatan terjadi pada asset lancar di angka 11,8\% akan tetapi hutang lancar naik sebesar 39\%, sehingga ini terus membuat current ratio perusahaan menjadi menurun setelah tahun 2015 .

2. Acid Test Ratio

Angka ini terus meningkat setiap tahunnya dan paling tinggi pada tahun 2017 mencapai 2,49X yang berarti PT HM Sampoerna, Tbk mampu menutupi hutang jangka pendeknya lebih dari 2 setengah dari seluruh hutangnya.

\section{Analisis Kebangkrutan}

Analisis kebangkrutan adalah alat yang digunakan untuk meramalkan kebangkrutan perusahaan. perhitungan analisis kebangkrutan dapat dilihat pada table berikut : 
Tabel 1.2

Perhitungan Analisis Kebangkrutan

\begin{tabular}{|l|r|r|r|r|r|}
\hline & \multicolumn{5}{|c|}{$\begin{array}{c}\text { Analisis Kebangkrutan PT. } \\
\text { HM Sampoerna Tbk. }\end{array}$} \\
\cline { 2 - 6 } & $\mathbf{2 0 1 7}$ & $\mathbf{2 0 1 6}$ & $\mathbf{2 0 1 5}$ & $\mathbf{2 0 1 4}$ & $\mathbf{2 0 1 3}$ \\
\hline X1 & 0.48 & 0.49 & 0.55 & 0.02 & 0.02 \\
X2 & 0.29 & 0.30 & 0.27 & 0.43 & 0.47 \\
X3 & 0.39 & 0.40 & 0.37 & 0.48 & 0.53 \\
X4 & 2.32 & 2.51 & 3.49 & 0.04 & 0.04 \\
X5 & 2.30 & 2.25 & 2.34 & 2.84 & 2.74 \\
\hline
\end{tabular}

\begin{tabular}{|c|l|}
\hline Tahun 2013 & 5.20 \\
Tahun 2014 & 5.09 \\
Tahun 2015 & 6.69 \\
Tahun 2016 & 6.08 \\
Tahun 2017 & 5.97 \\
\hline
\end{tabular}

Pada tahun 2016 - 2017 nilai z score menurun di angka 6,08 hal ini juga disebabkan oleh kenaikan pada total hutang pada tahun tesebut dan pada tahun 2017 berdasarkan analisis kebangkrutan PT HM Sampoerna, Tbk mengalami penurunan lagi mencapai 5,97 hal ini disebabkan oleh menurunnya harga per lembar saham PT HM Sampoerna, Tbk yang mencapai angka Rp. 3.000,- pada 30 Desember 2017 dan juga menurunnya total asset terutama pada asset tetap yang menurun pada tahun tersebut. Hal ini sangatlah tidak baik bagi perusahaan karena terus mengalami penurunan nilai $z$ score dari tahun 2016 dan 2017, meskipun nilai $z$ score perusahaan masih jauh dari angka kebangkrutan, ini menunjukkan ada penurunan kinerja pada PT HM Sampoerna, Tbk.

\section{KESIMPULAN DAN SARAN Kesimpulan}

1. Berdasarkan analisis strategi

Dilihat dari strategi pengembangan produk dan penetrasi pasar dapat mampu menaikkan tingkat penjualan setiap tahunnya selama periode $2013-2017$.

2. Berdasarkan analisis rasio laporan keuangan

Melihat dari keempat rasio likuiditas PT HM Sampoerna, Tbk menunjukkan hasil yang baik. Ini menunjukkan PT HM Sampoerna, Tbk mampu untuk menyediakan dana cepat, hal ini juga terlihat baik bagi para investor dan kreditor.

3. Berdasarkan analisis kebangkrutan

Berdasarkan analisis kebangkrutan Edward I. Altman, PT HM Sampoerna berada jauh dari tingkat kebangkrutan hal ini dapat dilihat dari jauhnya hasil $z$ score dengan $z$ score tingkat kebangkrutan. Meskipun PT HM Sampoerna, Tbk berada jauh dari kebangkrutan tetapi ada penurunan hasil $z$ score yang terjadi mulai tahun 2014, 2016 dan 2017 yaitu sebesar 5,09, 6,08 dan 5,97. hal ini yang harus menjadi perhatian PT HM Sampoerna, Tbk karena dalam tiga tahun terakhir mengalami penurunan.

\section{Saran}

Berdasarkan simpulan diatas penulis dapat memberikan saran kepada PT HM Sampoerna, Tbk untuk melakukan hal sebagai berikut :

1. Meningkatkan jumlah asset lancarnya untuk likuiditasnya.

2. Mengurangi jumlah hutang agar tidak terjadi leverage fluktuatif dan meningkatakan likuiditas.

3. Memperbaiki masalah penurunan kinerja pada metode kebangrutan.

\section{DAFTAR PUSTAKA}

Afriyeni, E. (2008). Penilaian Kinerja Keuangan Dengan Menggunakan Analisis Rasio. Jurnal Ekonomi dan Bisnis, 3 (2), 109-118.

Altman, Edward I. (1968). Financial Ratios, Discriminant Analysis and the Prediction of Corporate Bankruptcy. The Journal of Finance, 23 (4), 589-609. 
Bernard, Healy, Palepu. (2004). Business analysis and valuation using financial statements, edisi 9. USA : Thomson South Western.

Ikatan Akuntan Indonesia. (2002). Standar Akuntansi Keuangan. Jakarta: Salemba Empat.

Pearce, J. A. \& Robinson, R. B. (2013). Strategic Management : Formulation, Implementation, and Control, 13th edition. New York: McGraw Hill

Porter, M. E. (1980). Competitive Strategy: Techniques for Analyzing Industries and Competitors, $1^{\text {st }}$ edition. New York: The Free Press

Porter, M. E. (1985). Competitive Advantage : Creating and Sustaining Superior Performance, 1 st edition. New York: The Free Press.

https://www.bps.go.id/statictable/2009/02/24/1286/realisasi-penerimaan-negara-milyarrupiah-2007-2018.html/ Retrieved Oktober 11, 2019

http://bentoel.co.id/id/ Retrieved November 25, 2018

https://databoks.katadata.co.id/datapublish/2016/08/23/sampoerna-kuasai-35-persen-pangsarokok-nasional/ Retrieved Oktober 11, 2019

https://www.bps.go.id/statictable/2009/02/24/1286/realisasi-penerimaan-negara-milyarrupiah-2007-2018.html/ Retrieved Oktober 11, 2019

http://www.gudanggaramtbk.com/ Retrieved November 25, 2018

http://www.idx.co.id/ Retrieved November 25, 2018

http://www.sampoerna.com/id_id/pages/homepage.aspx Retrieved November 25, 2018 